\title{
A dinâmica regional nas relações internacionais
}

The regional dynamics in international relations

Elói Martins Senhoras ${ }^{1}$

\section{RESUMO}

O presente artigo de revisão discute os principais conceitos de teorização escalar sobre o papel da dinâmica regional nas relações internacionais por meio, tanto, de uma breve identificação dos principais padrões escalares que impactam na espacialização internacional do poder no sistema internacional, quanto, da análise do fenômeno da regionalização internacional a partir de três ondas regionais de longa duração.

Palavras chave: região internacional; regionalismo; integração regional.

\begin{abstract}
This review article discusses the main concepts of scale theorization on the role of regional dynamic in international relations through a brief identification of the main scale patterns that impact on the international spatial distribution of power in the international system, as well as an analysis of the international regionalization phenomenon taking for granted three regional long-term waves.
\end{abstract}

Keywords: international region; regionalism; regional integration.

\section{Introdução}

As espacialidades produzidas ao longo da formação histórica de distintos sistemas de poder periodizados pelas arquiteturas institucionais de impérios, cidadesestados, feudos e estados nacionais, têm sido organizadas diversamente em cada período histórico e ciclo hegemônico de poder segundo padrões funcionais específicos de relacionamento das políticas internas e políticas externas.

No feudalismo, as relações de autoridade senhor-vassalo consolidaram uma espacialidade local e regional altamente descentralizada, sem fronteiras definidas e muitas vezes sobrepostas de controle político e legal que foram radicalmente diferentes

\footnotetext{
${ }^{1}$ Elói Martins Senhoras é economista e cientista político, especialista, mestre, doutor e pós-doutor em Ciências Jurídicas. É professor universitário em cursos de graduação e pós-graduação stricto e lato sensu da Universidade Federal de Roraima (UFRR), Boa Vista, Brasil. 0 autor agradece à bolsa da Fundação de Amparo à Pesquisa do Estado de São Paulo (FAPESP) para o desenvolvimento da presente pesquisa. E-mail para contato: eloisenhoras@gmail.com.
} 
da organização do espaço político anterior do Império Romano ou posterior da Renascença (RUGGIE, 1993).

No capitalismo, por sua vez, a principal característica do Estado Moderno foi consolidar o seu poder e sua autoridade espacial em uma base territorial bem definida, portanto em um ponto fixo e único, que delimitou as fronteiras entre o nacional e o internacional, propiciando a conformação de diferentes dinâmicas internacionais alicerçadas por forças plurilaterais, regionais e multilaterais.

As distintas espacializações dinâmicas manifestadas com a evolução das relações internacionais podem ser compreendidas como o resultado combinado de influências de longa duração que se estruturaram devido, tanto aos centros de poder político dos ciclos hegemônicos ibérico, britânico e americano, quanto às distintas lógicas econômicas do capitalismo materializadas no capitalismo mercantil, capitalismo industrial e capitalismo financeiro.

Em um primeiro momento, no período sincrônico do capitalismo mercantil e do ciclo hegemônico ibérico, os padrões restritos de relacionamento dinâmico nas relações internacionais, seja entre as metrópoles europeias, seja das metrópoles europeias com suas colônias americanas, foram construídos por meio de um regime plurilateral de relações internacionais que se manifestou por um padrão verticalizado de competição e coerção política com o uso da força e por um padrão de interdependência econômica seletiva de Pactos Coloniais entre os emergentes Estados Europeus e as terras do Novo Mundo.

Em um segundo momento, durante o capitalismo industrial constituído ao longo do ciclo hegemônico britânico, as relações internacionais passaram a se estruturar de maneira incremental a partir de uma espacialização multilateral em razão da difusão do liberalismo econômico e da formação de uma divisão internacional do trabalho com as Revoluções Industriais, e da espacialização regional devido às dinâmicas econômicas e políticas de regionalização das políticas neocoloniais europeias na exploração da África, Ásia e Oceania.

Em um terceiro momento, no emergente capitalismo financeiro próprio do ciclo hegemônico americano, o dinamismo das relações internacionais passou a estar atrelado a partir da década de 1940 à difusão de uma espacialização do poder segundo uma arquitetura multilateral, muito embora tenha pendularmente sido fragmentada pela conformação de uma bipolaridade entre um bloco capitalista e outro socialista até a 
década de 1990, e, internamente aos blocos por dinâmicas plurilaterais de natureza geoeconômica e política concentradas no eixo do Pacífico a partir da década de 1980, bem como por dinâmicas de um regionalismo fechado (1950 a 1980) ou de um regionalismo aberto (1990 até os dias atuais).

Com o crescente processo de globalização, que erode as bases conceituais até então hegemônicas, bem como as bases políticas e institucionais das representações espaciais, os tradicionais estudos embasados nos Estados territoriais têm cedido espaço para outros "centros de poder" articulados a escalas mais abrangentes de caráter internacional que não necessariamente envolvem dinâmicas multilaterais, seja, em espaços regionais que buscam consolidar políticas de cooperação e integração regional, seja em espaços plurilaterais não contínuos que findam desenvolver acordos mútuos de interesse comum.

Tomando como referência que a consolidação de Estados territoriais pelo Tratado de Vestefália no século XVI representou um marco de mudança na configuração do espaço na transição do feudalismo para o capitalismo, o presente artigo tem por objetivo discutir que a formação de regiões internacionais por meio de instituições internacionais que se estruturam no formato de blocos regionais tem representado o surgimento de uma nova espacialidade que é dinamizada por transformações territoriais na configuração interestatal.

As regiões internacionais são apresentadas neste artigo como objetos centrais para os estudos com enfoque internacional, representando uma escala elástica que aborda desde micro espaços de aglomeração local e regional de atores subnacionais com projeção nas relações internacionais por meio de ações paradiplomáticas até macro espaços regionais conformados por arranjos contínuos ou mesmo descontínuos entre Estados Nacionais, constituídos por meio de negociações diplomáticas de natureza cooperativa e integrativa.

Os novos espaços regionais internacionais que têm surgido no sistema internacional apresentam semelhanças aos territórios antigos dos Estados Nacionais devido ao continuum histórico de transformações incrementais, mas um olhar mais apurado sobre os mesmos revela uma escala diferente e repleta de novas complexidades, haja vista que as políticas identificadas pelas estratégias de regionalismo fechado ou aberto buscam consolidar processos de cooperação e integração regional, 
muito embora, seja frequente a difusão de efeitos colaterais adversos aos objetivos iniciais, próprios de fragmentação regional.

Com base nestas discussões, o presente artigo foi estruturado em duas seções complementares, "Marcos de espacialização nas relações internacionais" e "O regional nas relações internacionais" que partiram de uma abordagem qualitativa de uso de dados primários (estatísticas) e dados secundários (livros, periódicos, dissertações e teses), fundamentando-se em um procedimento metodológico exploratório, descritivo e explicativo quanto aos fins que visou apresentar uma revisão sobre o papel da dinâmica regional nas relações internacionais.

\section{Marcos de espacialização nas relações internacionais}

Os estudos internacionalistas que tomam como referência a análise de determinadas escalas espaciais enquadram-se em um processo de incremental expansão discursiva e convergência analítica haja vista a dinâmica mutabilidade das relações internacionais presente nos últimos seis séculos ao longo de distintos ciclos hegemônicos.

As escalas espaciais presentes no estudo das relações internacionais são produzidas e não dadas ontologicamente a priori, pois são conteúdos e relações fluidas, contestadas e perpetuamente transgredidas, pois vários eventos que ocorrem em uma escala e têm implicações e consequências em outras, uma vez que muitas vezes, independentemente de qual é o sítio em que ocorre um evento, seus efeitos são sentidos em diferentes níveis escalares (SWYNGEDOUW, 1997).

Apesar de fluidas e interpostas entre si, toda escala é central e decisiva, material e simbolicamente, para estruturar os processos dinâmicos nas relações internacionais, segundo arquiteturas específicas e mutáveis que são construídas por distintos stakeholders ao longo do tempo em função da cristalização de diferentes padrões de difusão do poder no sistema internacional.

As escalas espaciais presentes nos estudos de relações internacionais obedecem a três marcos distintos de espacialização que levam em consideração a dinâmica de fluxos internacionais, tanto, nos espaços intranacionais (lugar, paisagem, região e território), quanto, nos espaços internacionais (espaços plurilateral, regional e multilateral), ou ainda, em espaços híbridos entre o espaço nacional e o internacional (fronteira). 


\section{Escalas intranacionais}

O estudo do espaço intranacional segundo diferentes escalas toma como referência distintos sistemas relacionais existentes na realidade a partir de apreensões analíticas que incluem desde óticas telescópicas até óticas microanalíticas, por meio do uso dos conceitos escalares de lugar, paisagem, região e território.

No espaço intranacional, o Estado-Nação representa o território de soberania, mediador entre o global e o local, sendo locus de intermediação ou filtragem de horizontalidades e verticalidades dos processos de cooperação e conflito promovidos por ações diplomáticas e paradiplomáticas que acabam se manifestando nas escalas do lugar, da paisagem, do território e da região.

Figura 1 - Escalas do Espaço Intranacional

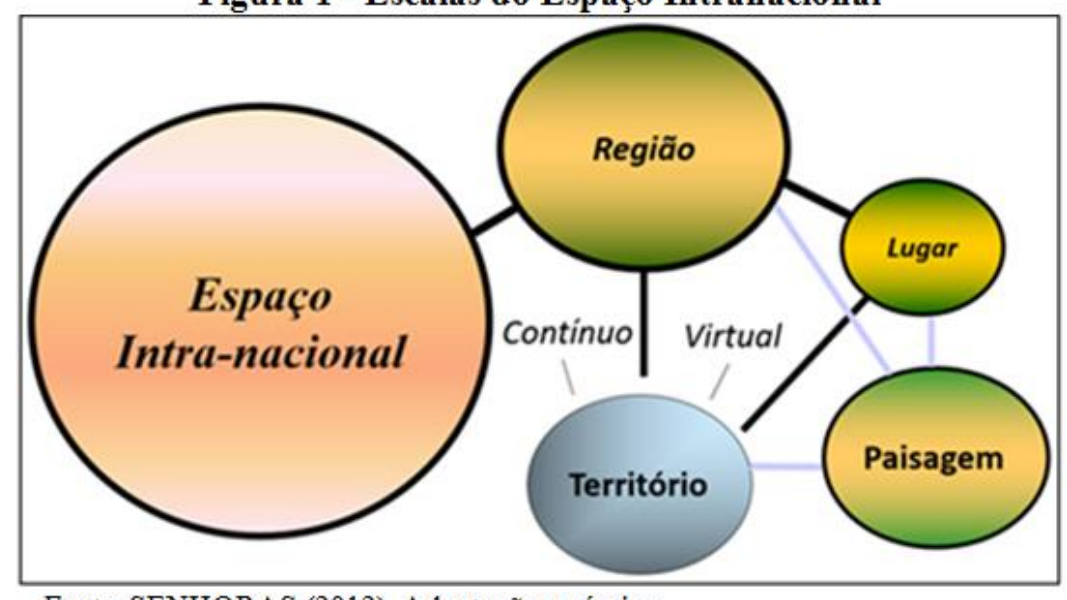

Fonte: SENHORAS (2012). Adaptações próprias.

Em primeiro lugar, o lugar se caracteriza como a escala de maior materialidade e concretude, propiciando uma microvisão dos fenômenos locais em que há uma tradicional escala de visualização de horizontalidades suscetível à crescente observação de verticalidades propiciadas por uma lógica glocal de interação entre o global e o local.

Em segundo lugar, a paisagem trata-se de uma escala elástica com distintos graus de materialidade e que repercutem, tanto, em micro, quanto, em macrovisões sobre as dimensões cultural e natural existentes na espacialidade, por meio de uma percepção sobre as rugosidades que se materializam nas relações homem-natureza, homemhomem, e natureza-natureza. 
Em terceiro lugar, o território é uma meso-escala analítica de agregação das relações que se fundamenta em uma formação histórica que é permeada por campos de poder, materializando-se em extensões contínuas, permeadas dentro de determinadas fronteiras, ou, mesmo, descontínuas, manifestadas virtualmente ou por polarizações, como o urbano e o rural, ou global e o local, as quais se conectam por meio de sistemas reticulares de fixos e fluxos, em que podem coexistir diversas territorialidades, sobrepostas ou paralelas (SAQUET, 2007).

Em quarto lugar, a região é uma meso-escala extremamente elástica de agregação da espacialidade, podendo ser qualquer área geográfica em que houver um recorte temático ou uma unidade distinta em virtude de determinadas características, pois se baseia em variáveis de similitude e semelhança que se manifestam em macro-regiões e micro-regiões, conforme o nível de agregação territorial de determinadas características comuns de geografía física ou humana (SENHORAS, 2009).

As quatro escalas abordadas embora representem padrões de espacialização intra-nacional, claramente possuem relevância para o estudo da Geografia das Relações Internacionais, uma vez que a capilaridade das redes infra-estruturais de transporte e comunicação possibilitam uma crescente quebra das barreiras nacionais que impactam diretamente na expansão bidireccional de articulações internacionais (de fora para dentro) e intranacionais (de dentro para fora).

\section{Escala híbrida da fronteira}

A fronteira internacional é uma escala marcada por uma dualidade intrínseca de contato e separação, que atrai e repele, justamente por representar espacial híbrido dinamizado por tanto, forças centrípetas de introversão, limitação e separação que se orientam pelos marcos abstratos do território nacional, quanto forças centrífugas de extroversão, contato e aproximação que se orienta pela cooperação e integração na internacionalização.

Ao serem dinamizadas por forças nacionais de natureza centrípeta em contraposição às forças internacionais de natureza centrífugas, as fronteiras são observadas por meio de marcos normativos, definidos pelas legislações nacionais quanto à extensão de faixas de segurança, bem como marcos fáticos existentes nas 
linhas de fronteira entre um país e outro, justamente, naqueles pontos fixos de interação mais intensa como as cidades gêmeas (SIMÕES, SENHORAS, 2014).

Conforme Senhoras (2013), a espacialização híbrida da fronteira internacional pode ser compreendida por uma extensão que se manifesta por 1 linha fronteiriça de separação e contato entre o doméstico e o estrangeiro e 2 faixas fronteiriças existentes em cada país definidas legalmente por discricionariedade nacional, as quais somadas conformam 1 zona (trans)fronteiriça em que se manifestam fluxos e dinâmicas de divergências e convergências.

Figura 2 - Espacialização híbrida da fronteira internacional

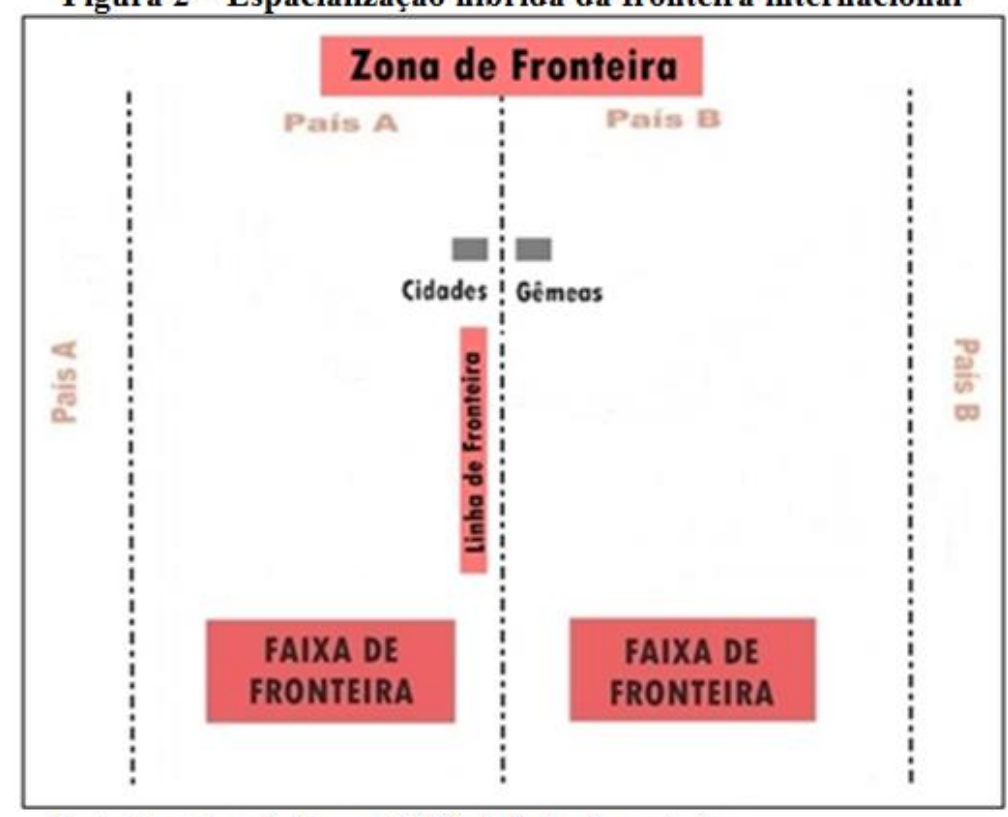

Fonte: Ferreira e Senhoras (2014). Adaptações próprias.

Em primeiro lugar, a linha de fronteira, por representar uma ampla extensão de separação e contato entre países, possui destacado interesse nos estudos de Geografia das Relações Internacionais por meio de análises sobre cidades gêmeas ${ }^{2}$, já que estas representam um conceito fronteiriço relevante sobre os limites da territorialização nacional, bem como, da reterritorialização internacional, pois são cidades presentes no limite internacional ou próximas do limite com cidades homólogas em país lindeiro.

Em segundo lugar, a faixa de fronteira representa uma extensão intra-nacional legalmente definida por cada país, na qual incidem princípios da segurança nacional na visão

\footnotetext{
${ }^{2}$ Embora a terminologia mais adequada para identificar as localidades transfronteiriças interdependentes seja cidades-irmãs e não necessariamente cidades-gêmeas - pois os polos têm desenvolvimento evolutivo acoplado, mas não necessariamente nascem iguais ou ao mesmo tempo - a literatura científica geográfica e internacionalista acabou consolidando a expressão, motivo pelo qual se mantém o seu uso popular. 0 surgimento paralelo de cidades em cada faixa da fronteira nacional antes de se tratar de uma horizontalidade produzida por um processo voluntário e natural, se refere a uma construção territorial criada por verticalidades artificialmente difundidas pela iniciativa reativa no tempo de governos nacionais ao estimular a formação de cidades-irmãs (SENHORAS, 2013).

Conjuntura Global, vol. 4 n.3, set./dez., 2015, p. 403-423. 
clássica da geografia política, em contraposição aos princípios de integração regional e multilateral, os quais obedecem à ótica geoeconômica de fomento comercial dos processos de liberalização e criação de regimes especiais aduaneiros, como Zonas de Processamento de Exportação (ZPE) e Áreas de Livre Comércio (ALCs), também conhecidas como Portos Livres (MAIESKI et al., 2013).

Em terceiro, a zona de fronteira é definida como um conceito geográfico transfronteiriço, potencialmente suscetível à existência de uma pluralidade de fluxos internacionais, expresso por meio de um padrão continuum de interação espacial entre países, no qual há a manifestação de um arranjo contíguo de faixas territoriais que se estendem ao longo da linha limite ou de contato da fronteira internacional até a extensão legal de cada uma das faixas de fronteira nacional (BRASIL, 2005).

Esta discussão aponta que a complexidade da escala híbrida da fronteira torna-se suscetível à análise da Geografia das Relações Internacionais por meio do uso da simplificação analítica dos marcos conceituais de linha, faixa, zona e cidades gêmeas, a qual é funcional para mostrar que a fronteira é porosa e permeável a verticalidades e horizontalidades criadas por fenômenos centralizados de natureza diplomática e descentralizados de natureza paradiplomática.

\section{Escalas internacionais}

As diferentes categorias escalares presentes na composição do sistema internacional são apreendidas pelo sentido das interações promovidas, em determinados campos de poder, de maneira centralizada por ações diplomáticas de Estados Nacionais e Organismos Supra Governamentais (OSGs), bem como, de maneira descentralizada por ações paradiplomáticas por diferentes stakeholders, como Empresas, Comunidades Epistêmicas e Organismos Não Governamentais (ONGs).

Embora o sistema internacional continue sendo balizado por uma clássica concepção geográfica estatal delimitada por fronteiras entre países, com um razoável poder explicativo de sua dinâmica, ela não é capaz de responder à alta velocidade das transformações da atual periodização da espacialização internacional, uma vez que surgem novos atores com ação geoestratégica concorrente ou paralela na potencialização de fluxos de distintas naturezas sobre o sistema internacional com materialização por meio das escalas multilateral, regional e plurilateral. 


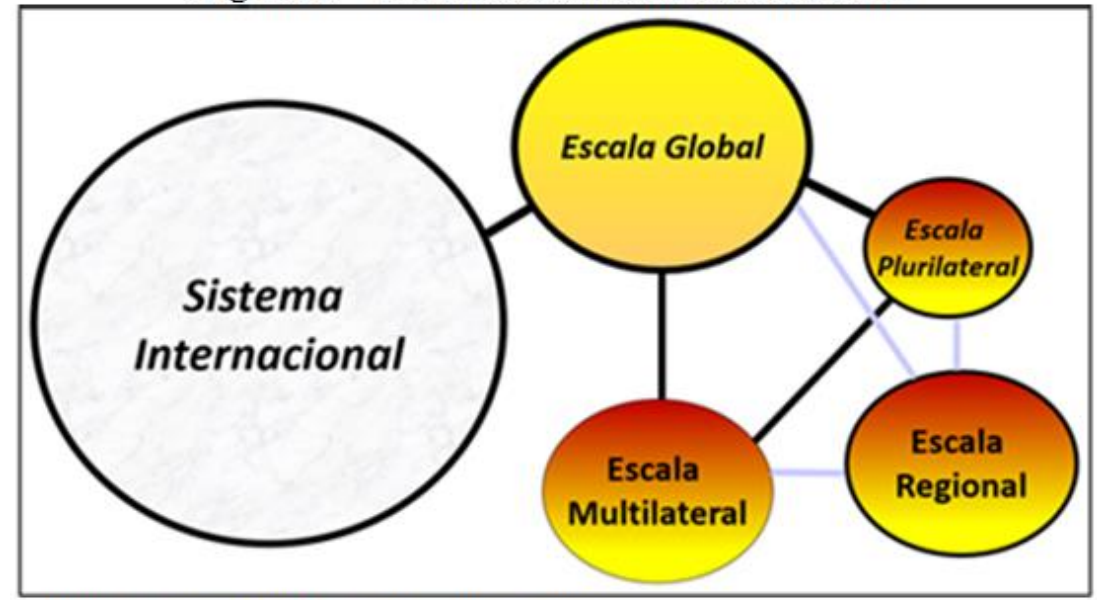

Fonte: Senhoras (2012). Adaptações próprias.

No sistema internacional, a escala global trata-se da escala internacional lato sensu, resultante de forças de curta e longa duração de integração que se manifestam em campos de poder produzidos em escalas internacionais stricto sensu com padrões específicos de dinamização plurilateral, regional e multilateral.

Em primeiro lugar, a escala plurilateral é uma micro escala internacional de integração profunda em que há uma convergência estratégica entre um número restrito de atores com natureza diplomática ou paradiplomática, distinguindo-se da escala regional pela menor presença de negociações internacionais entre os stakeholders e por não necessariamente existir proximidade geográfica e cultural entre os mesmos.

Em segundo lugar, a escala multilateral é uma macro escala internacional que tem passado por crescente expansão e adesão de atores nos últimos dois séculos desde a difusão do capitalismo liberal sob a égide dos ciclos hegemônicos britânico e americano por meio da conformação de regimes e organizações internacionais de governança global, os quais têm promovido um padrão de integração rasa em função do contato e da projeção internacional para múltiplos cantos do globo por parte de atores sem contiguidade espacial.

Em terceiro lugar, a escala regional trata-se de uma meso escala internacional que multirecorta o globo por meio de ondas de regionalização, as quais se manifestam por processos de integração profunda entre um número restrito de Estados Nacionais ou de outros stakerholders paradiplomáticos com proximidade geográfica ou cultural, justamente, quando as arenas multilaterais de governança são insuficientes para difundir a projeção internacional devido ao custo de transação existente pelo número elevado de atores (SENHORAS, VITTE, 2007).

Como resultado do complexo desenho espacial multirecortado por um emaranhado de forças presentes na projeção das escalas multilateral, regional e plurilateral no sistema internacional, a escala global pode ser compreendida como uma macro escala caótica, Conjuntura Global, vol. 4 n.3, set./dez., 2015, p. 403-423. 
conformando-se por um emaranhado campo de poder cuja espacialização se manifesta pela arquitetura de um spaghetti bowl.

Figura 4 - Spaghetti bowl das relações internacionais

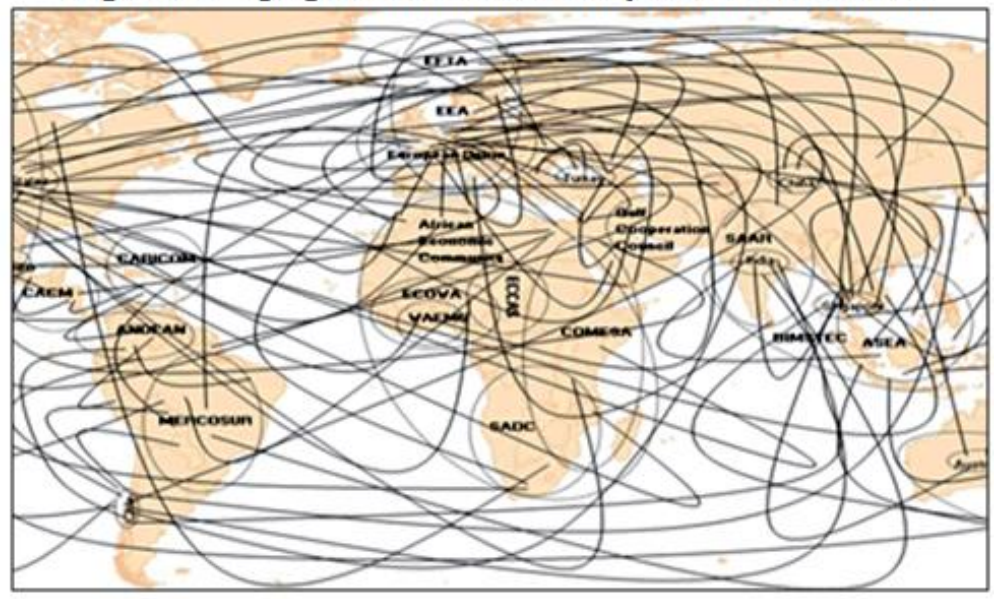

Fonte: SENHORAS (2008).

A espacialidade criada pelo emaranhado de negociações ou disputas simultâneas que recortam o sistema internacional, conferindo efeitos distintos, de maior interdependência ou autarquização das relações internacionais é identificada pelo termo de spaghetti bowl, pois demonstra como a forma relativamente caótica como o espaço internacional é conformado por uma rede multidimensional de ações internacionais de distintas naturezas promovidas por diferentes stakeholders.

A analogia da dinâmica das relações internacionais a um spaghetti bowl é relevante para demonstrar que o emaranhado reticular de acordos ou disputas presentes no globo corrobora para a conformação de dicotomias e contradições no sistema internacional, enquanto uma complexidade aberta e latente, que é meio e produto de vários fronts simultâneos de ações que se manifestam por processos superpostos de integração e fragmentação.

A evolução das relações internacionais em razão dos distintos frontes espaciais de internacionalização e de sua natureza ontológica pendular entre os clássicos dilemas da guerra e paz ou cooperação e conflito amalgama tendências contraditórias na projeção das ações e valores internacionais, tornando o sistema internacional em um dinâmico e incremental complexo cuja natureza não é a estabilidade ou o equilíbrio, mas antes, se caracteriza pelo dinamismo e mutabilidade. 


\section{0 regional nas relações internacionais}

As regiões têm se caracterizado como espaços com destacado papel na dinamização dos movimentos nas relações internacionais, haja vista que muitas empresas e atores subnacionais que se internacionalizam têm origem em regionalizações intranacionais de escala e escopo, além de praticamente todos os países do globo serem membros de um bloco regional, e muitos pertenceremm a mais de um, repercutindo em um sistema internacional que é influenciado crescentemente por iniciativas e instituições políticas presentes em determinados Complexos Regionais de Segurança e Desenvolvimento Econômico.

O termo região comporta diferentes significados nas relações internacionais, podendo exprimir o enfoque estático de áreas espaciais homogêneas ou heterogêneas de contiguidade continental, ou, ainda o enfoque dinâmico, seja de espaços intranacionais de conglomeração onde são projetadas redes internacionais de produção integrada, seja de macroconcepções espaciais onde são institucionalizados blocos regionais e complexos regionais de segurança.

De um lado, o enfoque estático de apreensão de regiões no sistema internacional trata-se de um formato analítico clássico que se desenvolveu em função de estudos geopolíticos, justamente com a finalidade de fornecer subsídios instrumentais ao policymaking para planejar a projeção das ações internacionais dos Estados Nacionais em um contexto claramente permeado por tensionamentos de uma agenda nacionalrealista.

De outro lado, o enfoque dinâmico de estudo sobre as regiões nas relações internacionais, por sua vez traz a identificação de, tanto, padrões espaciais gerais de envolvimento entre Estados Nacionais por meio de negociações diplomáticas que dão origem a acordos multitemáticos de cooperação e integração regional, quanto, padrões específicos de conglomeração intranacional por meio de cluster, arranjos produtivos locais e distritos industriais que acabam se manifestando internacionalmente por meio de ações paradiplomáticas normalmente de natureza econômica.

Como os enfoques estático e dinâmico de análise internacional permitem identificar as regiões como escalas intranacionais e internacionais que impactam distintamente na arquitetura das negociações e na dinâmica das relações internacionais, 
faz-se necessário compreender os seis conceitos basilares de sua instrumentalização: regionalismo; bloco regional; regionalismo internacional, cooperação, integração e fragmentação regional:

1) Regionalismo exprime a natureza política presente na manifestação espacial de uma região, sendo considerada toda ação ou negociação voluntária compartilhada com o objetivo fundamental de promover acordos de cooperação e/ou integração regional;

2) Bloco regional representa a manifestação institucionalizada de acordos interestatais que visam a promoção de interesses nacionais compartilhados dentro de uma agenda de cooperação e/ou integração regional;

3) Cooperação regional compreende toda agenda de colaboração específica entre distintos países ou atores descentralizados de uma região com o objetivo de avançar em interesses comuns, respeitados os princípios de voluntarismo, conveniência e flexibilidade;

4) Integração regional corresponde a uma estratégia institucional formalizada e compartilhada entre Estados Nacionais com o objetivo de se avançar em interesses comuns segundo um formato de integração profunda de ações, recursos e compromissos de longo prazo;

5) Fragmentação regional representa toda dimensão ex post de materialização das agendas ex ante de cooperação e/ou integração, cujo resultado se caracteriza por efeitos colaterais ou indesejáveis aos planejados;

6) Regionalização internacional caracteriza-se como o fenômeno relacional que materializa os tensionamentos dos vetores de cooperação e integração regional vis-à-vis aos vetores de fragmentação existentes dentro de um bloco regional.

Com base nestas definições, observa-se que o macroprocesso de regionalização internacional tem se tornado um fenômeno centrípeto que envolve o movimento de países em direção a uma maior integração mútua, a qual se materializa por meio de acordos e negociações institucionais formais e informais presentes em um bloco regional.

Enquanto processo informal, a regionalização internacional se manifesta como a projeção de atores descentralizados de natureza social e cultural, quando há mobilidade estudantil e de trabalho, embora seja essencialmente econômica e financeira, justamente 
quando as estratégias de paradiplomacia corporativa ou empresarial planejam a organização de cadeias globais de valor por meio da estruturação regional de redes internacionais de produção integrada (SENHORAS, 2010).

Enquanto processo formal, a regionalização internacional pode adquirir diferentes formas institucionais e diferentes níveis de profundidade, podendo materializar nos blocos regionais determinadas arquiteturas institucionais que podem partir do modelo de zona de livre comércio, passando por uma integração aduaneira, e finalmente podendo alcançar a integração econômica e integração física e talvez a política, o que confere ao regionalismo a característica de ter se tornado um fenômeno centrípeto, que envolve o movimento de países em direção a uma maior integração mútua.

\begin{tabular}{|c|c|}
\hline $\begin{array}{c}\text { Acordo de } \\
\text { Livre-comércio }\end{array}$ & $\begin{array}{l}\text { Ausência de barreiras tarifárias e não tarifárias entre os países. } \\
\text { Nesse tipo de acordo os países participantes podem concordar } \\
\text { em abolir totalmente todas as barreiras internas ao comércio } \\
\text { entre eles. }\end{array}$ \\
\hline $\begin{array}{l}\text { União aduaneira } \\
\text { ou Alfandegária }\end{array}$ & $\begin{array}{l}\text { Representa um passo adiante em relação à área de livre- } \\
\text { comércio, pois estabelece tarifas externas comuns para produtos } \\
\text { importados de terceiros países. }\end{array}$ \\
\hline $\begin{array}{r}\text { Mercado } \\
\text { Comum }\end{array}$ & $\begin{array}{l}\text { E um passo além da união aduaneira, uma vez que estabelece a } \\
\text { livre circulação de trabalhadores, serviços e capitais e implica } \\
\text { maior coordenação das políticas macroeconômicas, além da } \\
\text { harmonização das legislações nacionais (trabalhista, } \\
\text { previdenciária, tributária, etc). }\end{array}$ \\
\hline $\begin{array}{c}\text { União } \\
\text { econômica }\end{array}$ & $\begin{array}{l}\text { Prevê uma moeda e um Banco Central único para os países do } \\
\text { bloco. Para o seu funcionamento efetivo, os países devem } \\
\text { possuir níveis compatíveis de inflação, déficit público e taxa de } \\
\text { juros; as taxas de câmbio se tornam fixas entre esses países. }\end{array}$ \\
\hline $\begin{array}{l}\text { Integraçãoo } \\
\text { Física }\end{array}$ & $\begin{array}{l}\text { Prevê a construção de infraestrutura transnacional a partir de } \\
\text { redes integradas de base logística, energética e de comunicação } \\
\text { compartilhadas entre diversos países de uma região. }\end{array}$ \\
\hline $\begin{array}{l}\text { União política } \\
\text { ou confederação }\end{array}$ & $\begin{array}{l}\text { E o grau máximo de integração, onde os poderes legislativo, } \\
\text { executivo judiciário dos Estados-membros são vinculados a } \\
\text { abrir mão de suas soberanias individuais para dar lugar a uma } \\
\text { nova nação soberana que é o somatório das nacionalidades. }\end{array}$ \\
\hline
\end{tabular}

Fonte: Elaboração própria. Baseada em Beçak (2000).

No cruzamento entres os processos formais e informais de regionalização internacional onde estão manifestadas as distintas lógicas de atores diplomáticos e paradiplomáticos, a conformação de cúpulas inter-regionais tornou-se um instrumento funcional e flexível para avançar as negociações comerciais entre distintos blocos regionais (CARVALHO; SENHORAS, 2008). 
A combinação da motivação liberal de se administrar a crescente interdependência complexa do mundo com a motivação realista de busca de equilíbrio entre os blocos regionais conduziu ao surgimento de negociações inter-regionais que vão desde acordos bi-regionalistas, que abrangem diálogos bloco-bloco, até acordos trans-regionalistas, que designam arranjos mais difusos nos quais os países frequentemente negociam com outro bloco segundo uma capacidade individual desvencilhada dos interesses de sua região (GONZALEZ, 2007; HÄNGGI, 2000).

Frente aos processos formais e informais de regionalização e a expansão política dos regionalismos dentro de agendas cupulares de inter-regionalismos, o fenômeno lato sensu da regionalização do espaço internacional deve ser visto como resultado de múltiplos esforços para criar um regime regulatório de nível regional, o qual está suscetível aos avanços de integrações regionais de facto, embora, também aos recursos de eventuais fragmentações existentes.

\section{A regionalização das relações internacionais}

A escala espacial identificada como região originalmente tem sido utilizada para descrever uma porção do espaço relativamente homogênea e diferenciada de um entorno maior, servindo a qualificações muito diversas nos estudos que levam em consideração a evolução das relações intranacionais e internacionais.

O uso da região enquanto conceito instrumental tem menção desde os tempos do Império Romano quando as regiones eram denominações empregadas para referenciar as áreas de subordinação à hegemonia romana. Mesmo dispondo de administrações locais, as regiões presentes nos mapas romanos indicavam a extensão da representação espacial do poder hegemônico de Roma (GOMES, 1995).

No período medieval, as regiões tornaram-se importantes denominações que muito bem representavam a fragmentação espacial do poder em meio à descentralização política feudal e a autarquia econômica das localidades, justamente em um momento anterior à própria formação dos Estados Nacionais.

Com a edificação do capitalismo e a formação de territórios nacionais sob a égide de Estados Nacionais, o conceito de região tornou-se central para explicar distintas lógicas espaciais, tanto, de natureza intranacional por meio de marcos conceituais de 
microregiões e macroregiões, quanto, de natureza internacional por meio dos conceitos de regiões internacionais e panregiões.

Com o crescente processo de globalização, os estudos regionalistas baseados nas particularidades de determinados espaços intranacionais têm cedido ambiente para duas escalas regionais mais abrangentes de caráter internacional, seja a partir de microrregiões intranacionais que se configuram como áreas de aglomeração funcional para a projeção de determinadas ações internacionais, seja a partir de regiões internacionais ou pan-regiões que se caracterizam como espaços que visam projetar iniciativas de cooperação e integração regional.

Por um lado, as microrregiões intranacionais que funcionalmente se articulam a partir de cluster, arranjos produtivos locais ou distritos industriais se caracterizam como espaços de extroversão de uma nova geografia econômica nas relações internacionais em razão da capacidade de projetar redes globais de valor agregado por meio de ações paradiplomáticas de internacionalização empresarial.

Por outro lado, o surgimento de regiões internacionais e de pan-regiões a partir de acordos que objetivam projetar cooperação ou integração regional se caracteriza como uma tendência geo-histórica engendrada a partir de meados do século XX que tem se desenvolvido por meio de três grandes ondas de longa duração nas relações internacionais.

Estas três ondas de regionalização materializa um fenômeno centrípeto que envolve o movimento de países com o objetivo de promover maior cooperação e integração regional mútua, podendo ser caracterizado como um processo formal, dirigido por forças políticas de natureza diplomática, motivadas por preocupações econômicas, de segurança ou quaisquer outras, bem como um processo informal, guiado por forças essencialmente econômicas de natureza paradiplomática que visam expandir as redes de negócios internacionais. 


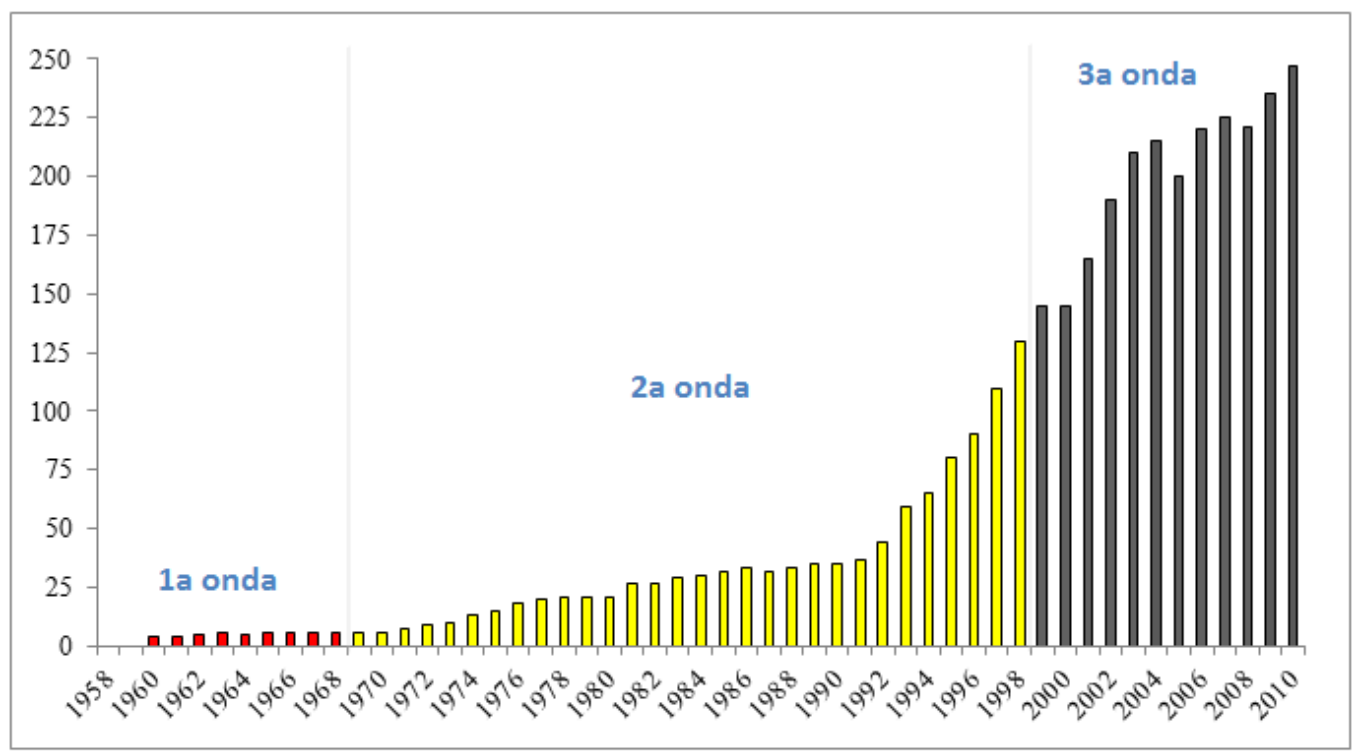

Fonte: Elaboração própria. Baseada em dados estatísticos da WTO (2010).

A primeira geração de regionalização internacional de acordos de cooperação e integração regional seria consequência direta do Pós II Guerra Mundial, frente aos acordos iniciais de cooperação regional na Europa e da vontade dos países subdesenvolvidos e em desenvolvimento em diminuir a dependência política e econômica que possuem com relação aos países avançados.

Tornou-se característico desta primeira geração a adoção de poucos acordos de cooperação política frente à proliferação de acordos econômicos preferenciais que visavam, tanto, desencorajar as importações, quanto, encorajar o desenvolvimento das indústrias nacionais a partir de estratégias de industrialização por substituição de importações, o que na maioria das vezes repercutiu em desvio de comércio internacional, tornando as dinâmicas de regionalismo fechado antagônicas às dinâmicas de difusão do multilateralismo.

A segunda onda de regionalização internacional surgiu profundamente diferente da primeira, pois as novas iniciativas regionais representaram uma tentativa de aprofundar acordos de cooperação e integração política e social, bem como de integração comercial por meio de uma dinâmica de regionalismo aberto, caracterizando as negociações regionais complementares às negociações multilaterais (SENHORAS, 2006; 2008).

A ênfase econômica dos acordos de regionalização internacional envolveu tanto países desenvolvidos como países em desenvolvimento, podendo ser caracterizadas as iniciativas de cooperação e integração regional como estratégias para liberalizar e abrir Conjuntura Global, vol. 4 n.3, set./dez., 2015, p. 403-423. 
as economias por meio da implementação de políticas export e foreign-investment-led, ao invés da promoção de estratégias de substituição de importações.

A terceira onda de regionalização internacional, por sua vez, é caracterizada por negociações bilaterais e plurilaterais entre Estados Nacionais que possuem uma agenda regional essencialmente comercial cuja natureza minilateralista está circunscrita a um momentum de crise institucional do multilateralismo e de promoção de cadeias globais de valor no comércio internacional a partir da consolidação paradiplomática de redes internacionais de produção integrada.

É típica desta terceira onda a projeção de acordos regionais entre países desenvolvidos e emergentes no eixo de acumulação do Pacífico, razão pela qual a dinâmica das relações internacionais torna-se permeada crescentemente por uma nova geoeconomia de cooperação e integração financeira e comercial e de uma nova geopolítica conflitiva no âmbito marítimo que se materializa na pan-região pacíficoasiática.

Com base na análise das três ondas de regionalização internacional observa-se que a dinâmica regional nas relações internacionais passou por significativas transformações que se relacionaram diretamente com a dinâmica multilateral, ora, confrontando, ora complementando as negociações e fóruns multilaterais que se desenvolvem a partir da década de 1940 e que acabam entrando em crise desde a década de 1990.

Se, desde o final da Segunda Guerra Mundial, algumas iniciativas de regionalização internacional foram desenvolvidas na Europa, América Latina e Ásia, somente, em uma segunda onda, na última década do século XX, é que se verificou uma ampla expansão de tendências regionais, envolvendo todos os continentes do planeta, muito embora a partir do primeiro quartil do século XXI a multilateralização de regionalismos internacionais tenha sido redirecionada para uma dinâmica plurilateral de regionalização em direção do eixo Pacífico-Asiático.

\section{Últimas considerações}

As regiões internacionais se referem a uma nova representação do espaço com efeitos específicos sobre as práticas espaciais de construção das ações nacionais, uma 
vez que, por um lado, as fronteiras dos Estados passam a ser consideradas mais como continuidades a limites, e por outro lado as políticas externas se pensam crescentemente em termos de uma interdependência complexa que cria sensibilidades e vulnerabilidades.

Com a consolidação de diferentes esquemas de regionalização, em suas distintas modalidades como macroprocessos ou microprocessos, transformações políticas e econômicas no sistema internacional surgiram e passaram a atingir os Estados Nacionais e os atores descentralizados subnacionais em seus processos de desenvolvimento e de tomada de decisões.

Sob o prisma diplomático, a macrorregionalização internacional pode ser entendida como o processo social pelo qual os agentes políticos de várias áreas nacionais procuram transferir as suas lealdades, expectativas e atividades políticas para um centro novo e mais abrangente, cujas instituições possuem ou pretendem jurisdição sobre os preexistentes Estados Nacionais (HAAS, 1958).

Sob o prisma paradiplomático, a microrregionalização internacional de determinadas regiões intranacionais é conformadora de uma nova geografia econômica do comércio e das finanças internacionais, na qual as relações internacionais passam a serem dinamizadas por processos de feudalização dos fluxos dentro de uma estrutural global-local (glocal) materializada por redes empresariais internacionais.

A conformação de distintos prismas para a compreensão do fenômeno da regionalização internacional é relevante para demonstrar a complexidade espacial do que se denomina espaço regional nas relações internacionais, já que não existe apenas um, mas ao menos dois espaços que apresentam características distintas, embora, complementares.

Por esta razão que o resultado da regionalização nas relações internacionais conforma uma arquitetura complexa nas relações internacionais que simultaneamente é permeada, tanto por agendas reticulares de cadeias globais de valor concentradas regionalmente no sistema internacional, quanto, por um emaranhado de negociações bilaterais, plurilaterais, regionais e inter-regionais que se multirecortam em um formato identificado como spaghetti bowl.

Embora complexa, a regionalização das relações internacionais caracteriza-se como um movimento de longa duração que vem se estruturando no sistema 
internacional por meio de três ondas desde meados do século $\mathrm{XX}$, razão pela qual adquiriu escala e escopo com dois terços do comércio mundial sendo processado dentro de regiões internacionais (HILAIRE; YANG, 2003).

Comportando um crescente número de empresas que compartilham redes internacionais de produção integrada, bem como uma majoritária participação dos Estados Nacionais, as negociações regionais e inter-regionais deixaram de serem espaços marginais nas relações internacionais, tornando-se o centro de uma agenda miniliteralista que avança frente à crise institucional do multilateralismo político e econômico.

Conclui-se que a regionalização internacional é um fenômeno processual extremamente relevante para explicar a evolução da dinâmica internacional, mesmo sendo permeado por uma complexa evolução de ondas de longa duração que refletiu na construção de espaços regionais e inter-regionais que vivem os dilemas da promoção das estratégias de integração regional em contraposição aos eventuais efeitos de fragmentação regional.

\section{Referências bibliográficas}

BEÇAK, P. Mercosul - uma experiência de integração regional. São Paulo: Contexto, 2000.

BRASIL. Ministério da Integração Nacional. Proposta de Reestruturação do Programa de Desenvolvimento da Faixa de Fronteira. Brasília: MI, 2005.

CARVALHO, P. N.; SENHORAS, E. M. "As negociações inter-regionais entre Europa, América Latina e Mercosul". Revista Intellector, vol. 5, n. 9, 2008.

FERREIRA, M. A. A.; SENHORAS, E. M. Comércio formiga na fronteira Brasil-Venezuela. Relatório de pesquisa de mestrado. Boa Vista: UFRR, 2014.

GOMES, P. C. C. "O conceito de região e sua discussão”. In: CASTRO, I. E.; GOMES, P. C. C.; CORREA, R. L. Geografia: conceitos e temas. Rio de Janeiro: Bertrand Brasil, 1995.

GONZÁLEZ, J. B. Espanha, Brasil e México: Atores vértices na dinamização do novo regionalismo euro-latinoamericano (1986-2006). Dissertação de Mestrado. São Paulo: Unesp, 2007. 
HAAS, E. B. The uniting of Europe: Political, Social and Economic Forces, 1950-1957. Stanford: Stanford University Press, 1958.

HÄNGGI, H. "Interregionalism: empirical and theoretical perspectives". In: Dollars, Democracy and Trade: External Influence on Economic Integration in the Americas Workshop. Los Angeles: PCIP, 2000.

HILAIRE, A.; YANG, Y. The United States and the New Regionalism/Bilateralism. Washington: IMF, 2003.

MAIESKI, E.; SENHORAS, E. M.; TREVISAN, R. "Dinâmica fronteiriça no arco norte brasileiro no contexto das Áreas de Livre Comércio". Cadernos de Finanças Públicas, vol. $12,2013$.

RUGGIE, J. G. "Territoriality and Beyond: Problematizing Modernity in International Relations". International Organization, vol. 47, n. 1, 1993.

SAQUET, M. A. Abordagens e concepções de território. São Paulo: Editora Expressão Popular, 2007.

SENHORAS, E. M. "Economia Política Internacional entre o Regionalismo e o Multilateralismo. Revista Carta Internacional, vol. 2, 2006.

SENHORAS, E. M. “A geoeconomia dos espaços regionais transnacionais”. In: TORRES, F. T. P. et al. (orgs.). Contribuições geográficas. Ubá: Editora Geographica, 2009.

SENHORAS, E. M. Prioridade sul-americana da agenda brasileira de negociações internacionais no contexto estratégico regional-multilateral de integração à economia mundial. Dissertação de Mestrado. São Paulo: UNESP, 2008.

SENHORAS, E. M. Uma agenda de estudos sobre a regionalização transnacional na América do Sul. Tese de doutorado. Campinas: UNICAMP, 2010.

SENHORAS, E. M. "Escalas da Geografia das Relações Internacionais". SelectedWorks of Elói Martins Senhoras. Boa Vista: UFRR, 2012. Disponível em: $<\underline{w w w . w o r k s . b e p r e s s . c o m / e l o i}>$. Acesso em 15/01/2015.

SENHORAS, E. M. "Dinâmica fronteiriça das cidades-gêmeas entre Brasil e Guyana". Revista GeoNorte, vol. 7, 2013.

SENHORAS, E. M.; VITTE. C. C. S. "A escala do regionalismo transnacional sob construção". Memórias del XI Encuentro de Geógrafos de América Latina. Bogotá: UNAL, 2007. 
SIMÕES, S. O.; SENHORAS, E. M. “Comércio formiga e os campos de poder na dinâmica fronteiriça: um estudo de caso na fronteira Guyana-Brasil”. Anais do XIII Seminário Internacional: Red Iberoamericana de Investigadores sobre Globalización y Território. Salvador: SEI, 2014.

SWYNGEDOUW, E. “Neither global nor local: 'globalization' and the politics of scale. In: COX, K. Spaces of globalization. New York: Guilford Press, 1997.

WTO - World Trade Organization. Statistics Database. Geneva: WTO, 2010. Disponível em: <www.wto.org $>$. Acesso 20/11/2015. 